\title{
Mathematics Is Science: A Topic Revisited in Context of FCS of India
}

\author{
Vinay Kumar \\ Scientist 'E', NIC, Block A, CGO Complex, Lodhi Road, New Delhi 110 003, India \\ E-mail: vinay.kumar@nic.in, vinay5861@gmail.com
}

\begin{abstract}
Mathematics is universally accepted as mother of all science. Despite that, Department of Personnel and Training (DOPT) has recently issued a circular mentioning that a person having master degree in mathematics cannot be considered for the post of scientists. The open question of 'Is mathematics a science?' is revisited in this paper under the new perspective to explore scientific practices that sans mathematics arrived knocking, challenging basic understanding of precision and practical sense that makes science. Considering the fact that in India, most crucial policy decisions at a higher level of abstraction in every conceivable arena of our national life are taken by either GOM (Group of Ministers) or GOS (Group of Secretaries), apprehension raises a basic query 'Who decides?' Some decision causes much unexpected consequence, which is noticed when it takes its toll and becomes virtually irreversible. This recent decision of Flexible Complementing Scheme (FCS), wherein mathematics is not considered as science, has potential to damage the very scientific culture and practices in India. This paper is an attempt to place mathematics in its right perspective and to highlight the damage that this decision might do. The paper also suggests ways to control the damage.
\end{abstract}

Index Terms - Natural Science, Basic Science, Flexible Complementing Scheme, Formal Science, Social Science, Techburea, Bureatech

\section{BACKGROUND}

A Flexible Complementing Scheme (FCS) for scientists is in position in some of the scientific Ministries/Departments of the Government of India and the same is governed by the guidelines issued by this DOPT under O.M. No.2/41/97-PIC dated the $9^{\text {th }}$ November, 1998 [7]. Besides other points detailed in the Office Memorandum (O.M.), it is also mentioned that a person must possess academic qualification of at least Master's degree in Natural/Agricultural Sciences or Bachelor's degree in Engineering/Technology/Medicine. The same detailing is reiterated in the O.M. No. AB1401713712008-Estt (RR) dated $10^{\text {th }}$ September, 2011 [6]. Subjects that come under natural/agricultural science are not enumerated in these O.M. [6, 7].

The O.M. [6, 7] further clarifies the activities and services that are considered as scientific in nature. These activities are: (a) Fundamental/basic research: Original investigation to gain new scientific knowledge, not necessarily directed towards any specific practical aim or application; working in scientific laboratories/ institutes, period spent on doctoral / post doctoral degrees in basic research after joining an organization, etc. would constitute field experience for the purpose of FCS.

(b) Applied Research: Original investigation to gain new scientific or technical knowledge directed towards a specific practical aim or objective; Working in scientific laboratories/ institutes, period spent on doctoral / post doctoral degrees in applied research after joining an organization etc. would constitute field experience for the purpose of FCS.

Recently, Department of Personnel and Training (DOPT) has come out with a circular [5] mentioning that those who have obtained Master degree in Mathematics are not eligible to be considered for the post of scientist in any departments of Government of India. There are other subjects as well like Computer Science, Information technology, Operation Research etc. However, since time immemorial, mathematics is treated as mother of all science and placed under the category of formal science. In view of this order, a number of questions arise naturally. What does constitute fundamental and basic research? Does mathematics play any role in establishing and gaining new scientific knowledge? Why basic science is not included along with natural/agricultural science in the list of academic qualifications? Is mathematics a science? What will be the impact of this decision on academic and scientific studies in India particularly in the area of mathematics and computer science? Answers to these questions are explored in this paper and few suggestions are placed which may be helpful in restoring the basic and deserved status to the subjects like mathematics and computer science in FCS.

Mathematics is there in nature and in every fabric of life. Let us take life of any individual Basic information related to a living being like 'Date of Birth', 'Age', 'Date of Joining Service', 'Length of Service' etc involves pure digital figures and mathematics. Mathematics involves every bit of life that encompasses 24 hours of each 365 days. Government Department handles statistics \& mathematics of wide range of administrative functions. Scope of mathematical applications remains inconclusively wide. It cannot be defined because it has no boundary and it is usually not problematic [1, 2, 27]. 
We all know what baldness means, despite the fact we cannot define exactly how many hairs on the head a nonbald person can lose before going bald. "One reason why mathematics enjoys special esteem, above all other sciences, is that its laws are absolutely certain and indisputable, while those of other sciences are to some extent debatable and in constant danger of being overthrown by newly discovered facts", opined by Albert Einstein [25].

By the way, what is science? The three essentials of science can be listed in the following order:

- Evidence that is gathered in experiments and observations.

- Evidence then leads to theories and theories that move from the specific to the general.

- The requirement that to falsify the theory, a counter example or contradicting evidence need to be placed.

Out of the three, the third one is referred as "falsifiability criterion". It sets science apart from superstition [21, 31]. It is also possible to first formulate a theory and then gather evidence instead of first gathering evidence and then propounding a theory based on the observations. The classic example of the former is the 'Theory of Relativity' by Albert Einstein and that of later is 'Quantum Mechanics'. The theory of falsifiability implies that scientific theories are constantly under threat to its falsification by arrival of new evidence. The theory of falsifiability is the kernel of science. Sometimes, people confound these core issues with less important points like where and how evidences are gathered. However it is gathered, evidence must be unambiguous and repeatable, and it must be objective to the extent that any two or more impartial observers must come to the same conclusion.

As it turns out, science does not require that evidence comes from nature. If one invents an imaginary world with clearly expressed, consistent rules, one can use the rules to gather meaningful evidence about that imaginary world and can shape a falsifiable theory based on observation. The result is scientific because the evidence appears as same to all observers and the derived theories can be falsified using evidence [14].

Science is split between two so called main groups, empirical science and formal science. Empirical sciences are like biology, chemistry, physics and so on, which also could be called natural sciences. Formal sciences on the other hand follow the same procedure to establish the truth but are not in particular aiming the natural world for example, Mathematics, Computer Science, and Statistics. Formal sciences tend to give the models and applications which empirical sciences apply to generate new knowledge from the natural world. Thus the very notion that formal science is not dealing with nature is a myth and many work has been presented at different time to dispel the myth. It is most probable that the present problem arisen due to FAQ issued by DOPT adhering to this myth.
The present anomaly can be resolved by just replacing the essential academic qualification of at least Master's degree in "Natural/Agricultural Sciences" with "Formal / Basic / Natural / Agricultural Sciences". Mathematics is very important for development of any scientific growth and technology development. As a human body is of no use without soul, any empirical science is of no consequence without mathematics because it can do nothing without mathematics.

This paper is organized in seven sections. An in depth analysis of open question 'whether Mathematics is a science' is done in Section 2. A comparative study between mathematics (a formal science) and natural science is carried out in Section 3. In Section 4, relevance of Mathematics in scientific research is discussed. The recent scientific policy of Government of India and its consequences is studied in the Section 5. A scientific measure is proposed in Section 6 as a remedial measure to control the consequences. The paper is concluded in the Section 7.

\section{IS MATHEMATICS A SCIENCE?}

Historically, mathematics is considered as a collection of formula for solving a problem like rules of differentiation, how to multiply two numbers together etc or perhaps providing a proof based on axiomatic model. Axiomatic model is based on abstract notions and 'self evident truth' $[8,9]$. In fact, none of these notions about mathematics is true in context of modern research mathematics.

These days, mathematics tends to be divided into two segments: applied and pure. Applied mathematics is the part of mathematics that deals with problems that arise out of empirical concerns: pure and applied statistics, differential equations, and the like. Pure mathematics deals with problems that arise out of theoretical frameworks, often purely mathematical. The distinction, however, is not absolute but largely conceptual. For example, at one time Number Theory was considered the most pure of pure mathematics, which had no possible practical application. Off late it has become the cornerstone of studies related to areas like modern cryptography, information hiding and information security and privacy $[17,18,23]$.

Mathematics plays a major support role in science and scientific development. It is mathematics (Statistics) that changed perception of 'medicine' from being an art to science [31]. A mathematician considers some specific examples (we call it observations), proceeds to find relationships if any, formulates some questions, both general and specific, and then finds how specifically it can be answered. Then it attempts to find a general statement (hypothesis) and proceeds to proof it. Failing to prove with experimentation, attempt is made to construct a counterexample (falsification and testing). This process continues until the mathematician finally obtains an argument establishing his/her hypothesis. Mathematician rejects it otherwise. 
Mathematics always attempts to "proof" a concept conclusively and imposes far more stringent standard than is met by any other science! Let us consider the "Newton's Law of Universal Gravitation" as an example. The 'universality' claim of this law is based on the assumption that it has never been contradicted. Compare this with 'Fermat's Last Theorem'. 350 years of being unable to find a counterexample or proof was not considered an evidence of truth or falsity. It was accepted only when a proof was produced and the proof was checked and verified.

It is typical Indian Scenario, internationally France and Russia is considered most advanced nations in mathematics. The core concern that mathematics is not getting its due lays the way mathematics is reported in research articles and books. It is reported more as tool rather than a concept and the way mathematics is exercised internationally. As resultant effect, everyone except the professional mathematical researcher tends to get a skewed, adequate and inaccurate view of mathematical research in the country. This in turn has led some philosophers to conclude that mathematics is not a science. This is also because of the Hilbert School, which from its beginnings and especially in the wake of the work of Goedel, Turing, Church, and others, abandoned the ideas of "true" and "false" in favor of the ideas of "provable", "disprovable", and "undecidable". The definition of science places a strong emphasis on truth, and so it would also seem to follow that, insofar as mathematics seems unconcerned with truth and falsity anyway, it could not be considered a science or a scientific pursuit $[12,22]$.

Demand for mathematical proof does not seriously distinguish mathematics from other sciences. Question is raised on the axioms in mathematics. It is said that axioms are arbitrary statement. This is again a myth. Axioms can be arbitrary statements, but they almost never are. The axioms of group theory were developed from the study of equations; they represented the minimum conditions on which the arguments would follow [10, 11]. And while one works with groups, these axioms are not changed. On the other hand, people are free to drop, discard, add, or remove axioms at will to produce other systems with which they can also work: this is the case of semi groups (obtained by removing one axiom), or ring theory (obtained by adding a number of axioms) [30, 33]. The application of this mathematical structure is very well known in the field of development of cryptography, which has become buzz word in the context of cyber security and information security. When a mathematical theory is derived from a real world situation in an attempt to abstract and study, the axioms seldom go unquestioned or unmodified. There is in fact a continual feedback and fine tuning between the mathematical theory and the real world [32].

Though mathematics normally refrains from saying "true" and "false", and usually talks about "provable" and "disprovable", it does not mean there is no contact or application with the outside world. Mathematical theorems are never simple declarative statements; rather, they are always implications. All mathematical theorems are of the form "If (some conditions are met), then (this conclusion will follow)." Moreover, this will hold true whenever we interpret the theory in a specific model.

There are certain instances found in the past mathematical proof where a mathematician inadvertently use specific properties of an interpretation and obtain a result which was found to be invalid in other interpretations. Classic example is Euclid geometry. It means mathematics follows the scientific method. Though it seems that mathematics lives in its own little world, away from real world, the truth is that, even in its "purest" guise, it keeps an eye out to reality for both applications and inspirations. In its "applied" guise there can be no doubt that it sticks close to reality, and that its assumptions, problems, and conclusions are continually tested and refined against that backdrop. Nonetheless, it is also different from other sciences in that its standards are a bit higher and a bit more certain. This is the strength of it and not a disqualifying property for it to be called as science.

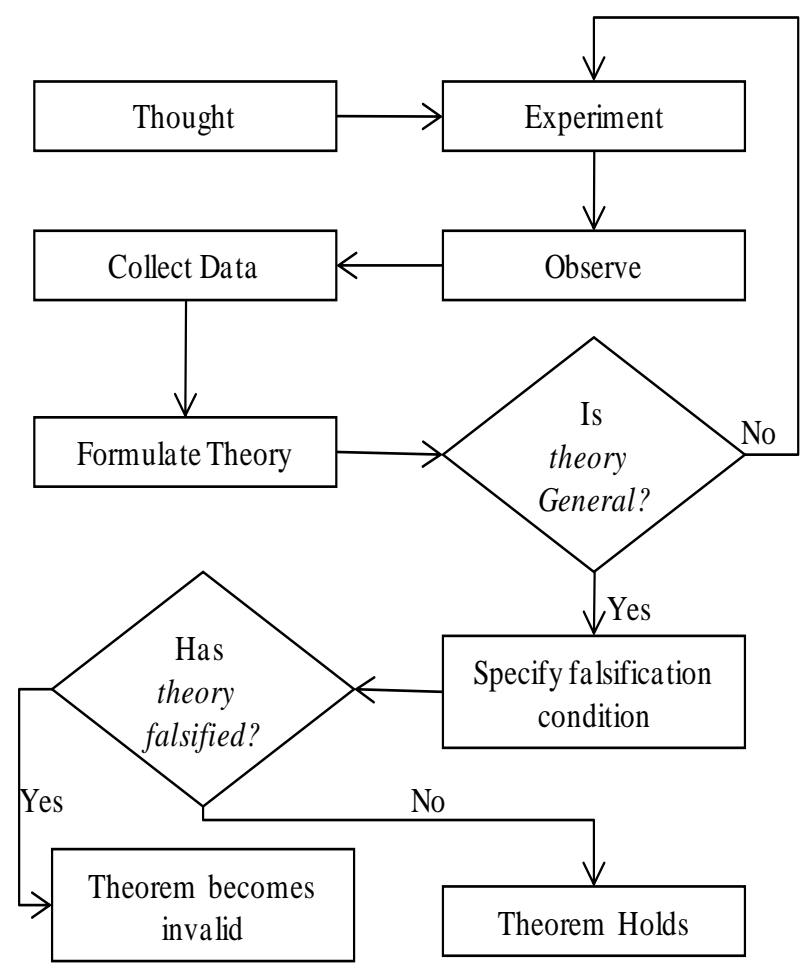

Figure 1: Scientific research procedure

So, coming back to our working definition of science, does mathematics meet the requirements? It attempts to distinguish true statements from false statements. However, we must understand here that a "true statement" does not refer to a theorem or lemma in isolation, but rather to the implicit statement given by a theorem, that whenever all axioms and hypothesis are interpreted in such a way as to make them true, then the corresponding interpretation of the conclusion from the theorem will also be true. Likewise, "false statement" 
would mean that there is at least one interpretation of the axioms and hypothesis which makes them true, while at the same time making the conclusion false.

And mathematics has a very systematic way of validating its claims, again through the use of proofs; false claims may be identified by presenting counterexamples or pointing out gaps in proofs. This is done in a systematic and commonly accepted way.

\section{NATURAL SCIENCE AND MATHEMATICS}

Natural sciences are branches of science that seek to elucidate the rules that govern the natural world by using empirical and scientific methods. The mathematics sometimes referred as formal science by those set of philosophers, who simply believe that "Mathematics is a formal abstraction of quantity and logical deduction. There is no concept of evidence within it. Everything is deductive. Deduction is a fundamentally different kind of knowledge than observation. You can do it all in your head, with your eyes shut, in a sensory deprivation tank, at least in principle. There's no such thing as mathematical hypotheses and experiments" [9]. Those who have studied and researched mathematics and followed its application in various other fields may find the above argument highly misplaced [10]. Here are some questions related to relevancy of mathematics in the field of science, research and nature, which were also placed before researchers from NIC and academicians from Indian universities. They were unanimous in their response confirming that mathematics is an integral part for all scientific pursuit. Readers are requested to answer these questions in yes/no or assess it in scale on Ten points in such a way that Ten indicates mathematics is essentially required and 0 indicates that mathematics is not required at all, and assess the relevancy of mathematics.

- Can we think of any research in natural science without mathematics?

- In our daily life, can we find a single instance where we are not using mathematics or its application?

- Can we describe any natural phenomenon in authentic and scientific way, without using a mathematical model?

- Can we establish any research finding in any branch of natural science without help of mathematics?

- Can we say that a finding is scientific where any of the components used and results/observations noted is unscientific?

- Can we think of cyber security or information security that involves encryption algorithm and key without mathematics?

- Can we process the result of even that recruitment examination that selects/recommends candidates for high profile job of bureaucrats in India, without help of mathematics?

- Can we plan any development project; monitor its progress to ensure that the objective of the project is achieved, without the help of mathematics?
- Can we develop any metrics in any field of study/work without using the basic concept of mathematic?

- Can we say that mathematics has matured to that saturation level that now no research in mathematics is required?

- Can we say that mathematics has no role to play in the research/innovation in the field of Information Technology and computer science?

In the previous section, it is explained that all the three key elements of science: theory, evidence, and falsifiability are present in mathematics. Because of presence of these three elements in subjects like physics, chemistry, zoology, botany and medicine; they are treated as natural science. It is also true that people sometimes create an imaginary world and falsely claim that it represents nature, but that is a separate issue and right now it is not the subject matter of this paper. There are various reliable ways to establish whether a mathematical model has a corollary in nature.

An inclusive diagram showing relationship of mathematics with other sciences is shown in the Figure 2. If we look at mathematics as an imaginary world with no connection to reality, we can still do science with it. Let's call that "Platonic mathematics." In this context, platonic mathematics is the kind of mathematics having no essential connection with the physical world. I say "essential connection" because links between nature and esoteric mathematical notions spring up in unexpected places, like the surprising connection between locusts and prime numbers. If instead we claim that mathematics is nature's language, then we can explore nature through mathematics, and again, it is a legitimate science. Let us call that "natural mathematics". A natural mathematics is the kind of mathematics arising from the uncanny efficiency with which mathematics describes nature.

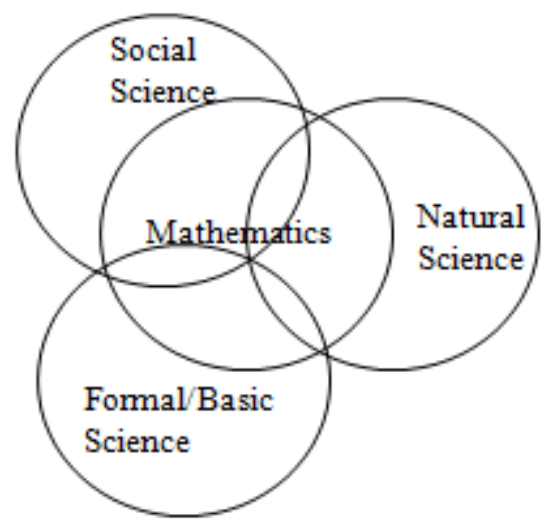

Figure 2: Inclusiveness of mathematics in other scientific fields

Let us now express a hypothesis about a system disconnected from nature, then gather evidence from the system. My intent is to show that all essential scientific criteria can be met by a purely mathematical idea. Let us take for example Euler's prime generator function and let us claim that the function $f(x)=x^{2}+x+41$ (from Euler) 
will produce only prime numbers where $\mathrm{x}$ is a natural numbers. Obviously, this claim has all the properties required for science: it poses a theory that is testable using evidence and if the evidence contradicts it, the theory is falsified. It also possesses a diligence factor i.e. if the experiment is not conducted with sufficient zeal, it may produce an unreliable result. This remarkable function will generate a prime result for each argument in the range $0<=x<=39$, but at $x=40$ it fails. Back in the days of hand computation, several days might be required to generate and test the results. Euler's prime generator makes a statement about pure mathematics, not nature, yet it is testable and falsifiable in a scientific way.

\section{Relevance of Mathematics In SCIENTIFIC RESEARCH}

Many scientists regard mathematics as the language of nature. Those who do not know mathematics it is difficult to get across a real feeling as to the beauty, the deepest beauty, of nature. If you want to learn about nature, to appreciate nature, it is necessary to understand the language that she speaks in. This was said by Richard Feynman - Nobel Prize winner, about mathematics. As we learn more about nature, it becomes increasingly apparent that an accurate statement about nature is necessarily mathematical. Anything else is an approximation [28].

Let us discuss a story of one of the more beautiful convergences of mathematics and nature, one that vindicated Dirac's belief and won him a unique place in the history of both physics and mathematics [13]. Let us think about the quantum world, in brief, to put the above statement in perspective. Physics at a large scale is made up of continuous quantities. You can measure a meter, or a millimeter, or a micrometer, and all these measurements have meaning and can be added up. But at a very small scale, the universe acts differently. To give a sense of this microscopic world, let us use the following thought experiment $[2,3]$ :

- Say that individual atoms are coins that can only have two states — "heads" or "tails."

- Further, say that an atom that is "heads" has a value of one and "tails" has a value of zero.

- Nature flips the atoms in a completely unbiased way, so a large collection of atoms has a probability value very likely to be near $1 / 2$.

- Even though a large collection of atoms should have an average value near $1 / 2$, a small, random probability exists for values other than $1 / 2$, which means quantum effects can sometimes influence the macroscopic world.

- Nature randomly flips the atoms, at times and places of her own choosing, and we cannot discover which atoms nature has flipped until we examine them.

At a large scale, we can rely on an object being the same from moment to moment, but as we magnify the picture, we eventually get to a scale at which matter is not continuous, but is broken up into little packets of matter and energy. This little packet is called "quanta" and its state depends on rules of probability. This is very simplified illustration to provide a sense of the quantum world. Because of the discontinuous nature of quantum theory, it seems the large-scale (macroscopic) and quantum worlds operate on different principles. We can have a kilogram of uranium, or a gram, or a tiny mote, but we will eventually get to a point at which we cannot measure the uranium on a continuous scale. More important, the uranium may not behave according to classical rules because at a random time it might turn into something else, like lead [4].

Quantum theory is based on probability and is discontinuous at small scales of space, time, mass and energy. In spite of the built-in uncertainties, the quantum theory is very successful at predicting certain aspects of the world around us, and most of modern technology derives from our understanding of quantum theory. It leads to two kinds of physical theories: i) those that work at a large scale, and ii) those that work at the scale of individual atoms. Unfortunately for physics, these theories are incompatible. The very successful theory of relativity is not expressible in quantum terms, and vice versa. Even though we do not have a unified theory that works at all scales, physicists have discovered elements of such a theory. One of these elements is an equation written by Paul Dirac in 1928 [4, 11]. Dirac's equation successfully predicts the behavior of particles moving at relativistic velocities, so to some degree it reconciles the relativistic and quantum views of reality and he won a Nobel Prize for his work in 1933. I am not reproducing the equation here. It means, the laws of nature should be expressed in beautiful equations.

Today, Information and Communication Technology (ICT) has become a buzzword in all walks of life. Governments across the globe are spending lots of scarce resources in terms of time and money on introducing egovernance in different departments of governance. Have we ever spared a few moments to assess the contribution of the mathematics, it played and it is playing in very evolution of this technology? See the Figure 3 below. It depicts how the concept of an element of a set finally led to the evolution of the modern age powerful computing device -what we refer as computer systems. Day by day the cost of this device is decreasing just because of the improvement in the integration technology whereby more and more chips are packed over smaller and smaller spaces on a board. It is referred as Large Scale Integration (LSI), Very Large Scale Integration (VLSI) and so on. It has ultimately led to the development of laptop, palmtop, PDA and many computer based gadgets. Read any book on digital electronics and discrete mathematics to have a taste of contribution of mathematics in the evolution of computer. 


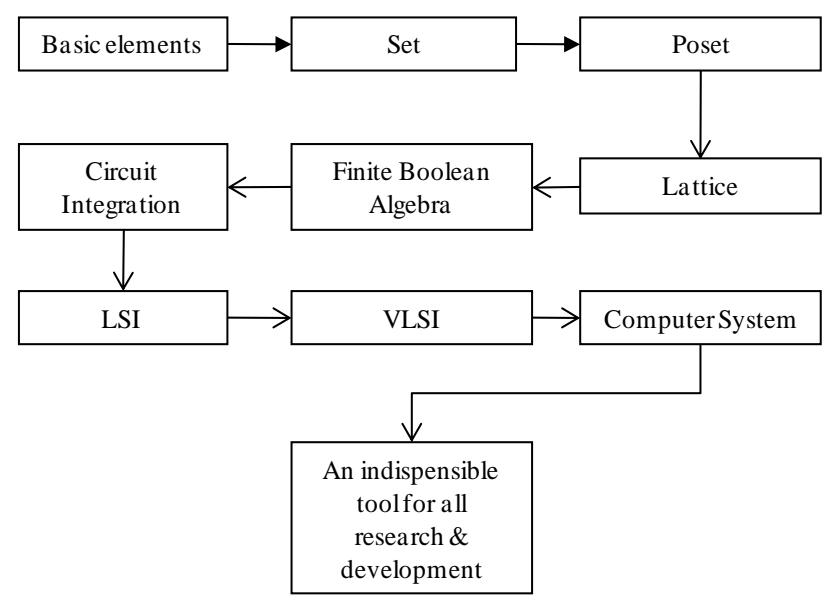

Figure 3: Evolution of computer from set theory

Another area in ICT is development of program to solve a problem. Development of program is based on the development of algorithm. There exist many algorithms to solve similar problems. Some of algorithms are better than other. But how to determine which one is better than which one? What is the metric that we use to measure that? Here again mathematics comes for rescue in form of complexity analysis which itself is based on the basic concept of growth of function.

Cyber security and cyber crimes are buzz words in ICT these days. The mechanism used to control these crimes and provide security against these crimes is based on mathematics. The entire world of cryptosystem (encryption, decryption and key) is based on modern algebra [20, 24]. The application of modern algebra is not limited to the world of encryption. Let us take the case of object oriented technology. The very concept of data hiding, inheritance, constructor, destructor, object derivation, polymorphism, virtualization etc are very much borrowed from the concept of the mathematical structures like: Groupoid, Semigroup, Monoid, Group, Abelian group, Ring, Field etc. [21].

In this digital world, we talk about paperless office, electronic file movement, electronic document repository, preservation of arts and artifacts in digital forms and similar other activities. The related issues are authentication of these documents and preservation of intellectual property right (IPR) especially in case of arts and artifacts. The digital signature is used for authentication purpose. Digital fingerprinting and digital watermarking is used for preservation of IPR. Modern mathematics is again here! It is the mathematics that helps us in evolving algorithm behind such technique [29]. Can we say that mathematics is not required for scientific research? In fact, it is absolutely right to say that mathematics is a language of nature and nothing exists without mathematics in this world.

\section{ReCEnt ScIENTIFIC Policy AND ITS CONSEQUENCE}

Science is a form of epistemology that, like any good epistemology, attempts to distinguish true statements from false statements and thereby leading to an accumulation of knowledge. One of the primary things that distinguish science from other epistemologies is that it is a) systematic and b) non-dogmatic [25, 26]. A proper science must have a means of validating its claims as well as a means of identifying and rejecting false claims. In the recent policy [6] and FAQ released subsequently [5], it appears that two are not in conformity of each other. Essential qualification required for a scientific post and activities that may be considered as scientific is mentioned in section 1 of this paper. Let us now see the other fine points of the policy.

- The benefits of FCS shall be extended only in such Departments as are involved in creating new scientific knowledge or innovative engineering, technological or medical techniques or which are predominantly involved in professional research and development and / or application of scientific knowledge. The modified criteria for identifying departments as scientific and technical and parameters for determining scientific activities and services, scientists and engineers and scientific posts will be as in the Annexure II to this scheme.

- The institutions referred to as S\&T would be characterized by pursuit of excellence;

- They should be involved in creating new scientific knowledge or innovative engineering, technological or medical techniques or which are predominantly involved in professional research and development work.

- The scientific culture is characterized by a few salient aspects, namely the persons involved are highly qualified and skilled technical personnel, involved in creative and innovative activity, they are willing to be judged based on the basis of merit and competence rather than on the basis of seniority and a hierarchical structure;

- The criteria could cover the aims and objectives of the institution/organization, qualifications of the personnel, qualitative requirements for performance of various types of activities etc.

Besides fundamental research and applied research as mentioned in the section 1 of this paper, the policy also mentions that experimental development should also be considered as scientific research and activity. It states that

- Application of scientific knowledge directed towards producing new or substantially improved materials, devices, products, processes, systems or services; 'field experience' would depend on the work profile of the Department . The defining factor would be that the work is not of routine use of scientific knowledge but involves application of scientific knowledge for creation of new / innovative systems, practices, models.

- S\&T activities which are directly linked to R\&D in terms of promoting the scientific activities and services. Working in $\mathrm{R} \& \mathrm{D}$ laboratories and institutions, scientific projects being operated in 
mission mode, working on international collaboration $\mathrm{R} \& \mathrm{D}$ projects etc. would constitute the field experience under FCS.

Further, the DOPT Circular [6] reiterates that only such scientists would be eligible for promotion under the scheme, who not only possess the requisite qualifications, and are engaged in Scientific and innovative activities as distinct from the mere application of technical knowledge; and further, the function discharged by them are relatable/ identifiable to their academic specialization. Then, it mentions about the criteria for an organization to be covered under FCS. This I am not discussing here because the theme of the paper is the non consideration of mathematics as science subject under this policy.

The problem arises when the policy [6] is read with item no. 5 of the FAQ [5] which clarifies that a person with master degree in mathematics, computer application; information technology (and others) is not eligible for the post of scientist. Is not it confusing? How can any basic, applied or experimental research for either generation of new knowledge or improvement of algorithm for solving any fundamental problem can be carried out without the knowledge of mathematics, IT and computer application?

The FAQ [5] seems to be based on the basic premises that computer scientists in India are merely using the software and computer hardware produced outside the country and they do not need to work towards development of such tools on their own in the country. It is highly misplaced concept. There are number of IT products which are indigenously developed. Some are in use and are very popular. A few examples are: super computer from BARC and CDAC, Railways Reservation system from CRIS, various online application systems from NIC. Many software tools and hardware were developed but could not see the light of the day due to influences of Techburea and Bureatech on decision making process and their hidden agenda [16, 19]. Who are these Techburea and Bureatech?

Many bureaucrats, after learning a few catch words through sponsored seminars and workshops, have started behaving themselves as IT experts. They think that IT is magic wand and it can do anything what they desire! Like CHIRAG of ALLAUDDIN! They ignore good and technical advice from those who understand the technology. They have agenda of spending budget and at the end of the year decorating the Annual Progress Report (APR) with tall claim of executing project of the tune of so and so amount. The class of professionals is called Bureatech. There is another class of professionals who neither understand technology nor possess the basic administrative skill of a bureaucrat. They are good in misleading the bureaucrat by posing as technocrat and liaison with e-vultures to prepare imposing and convincing project proposals that easily gets approved by Bureatech. Before technical experts they behave like project manager and dictate terms to prepare implementation strategy which is less technical and more of a publicity kind. They form a very good team with evultures to sale everything non-saleable. Techburea is the name of this class of professionals.

As vulture descends to the site where it senses any carcasses, there are agencies that smell the amount to be spent by the government departments on any egovernance projects and approach without invitation. They are well versed in coordinating with Techburea. They are known as e-vultures. These e-vultures are working overtime to give a new meaning to the well coined term PPP (public private participation) as public private partying. The emergence of this new breed of professionals called Techburea, Bureatech and e-vultures is doing more disservice to the nation. This recent policy is another step for furthering their interest. Because of this policy, there will be little or no interest towards the basic research in India and for every silly thing that needs innovation, dependency on import from outside will increase. Indian talents will simply get reduced to operator class that will be trained to use the products developed outside. It is right time to think that despite claiming ourselves as IT superpower, we do not have a single indigenous Operating System in common use. We do not have an editor of our own that is commonly used. We do not have a single indigenous CPU chips developed till yet despite the fact that our own talent is doing the same thing abroad. It is simply because of our policy that creates environment for that. The recent policy is going to be another or may be final nail in the coffin of scientific culture in India particularly for basic and fundamental research.

Any scientific policy must be scientific in a way that it must identify scientifically that which subject is scientific and which area of activities are scientific. Area of activities is cohesively dependent on the subject field. In the multi-disciplinary research activities, it is not possible to compartmentalize that a subject $\mathrm{X}$ is relevant and another subject $\mathrm{Y}$ is not relevant. Since mathematics is the language of nature, it is rightly bestowed with the motherhood by saying that "Mathematics is called mother of all sciences". Mathematics brings in precision in problem definition. It brings us to surrealistic to realistic world. In its absences scientific quest will remain incomplete which brings us at the threshold of a problem of enormous dimension.

\section{PROPOSED REMEDIAL ACTION}

In north Indian village, a native saying is very popular. It goes like this. A person claimed that his one of the hens, which just died then, had three legs. He insisted for the hefty compensation for that keeping in mind its uniqueness. People around tried to convince him that the hen had only two legs and not three which he is claiming. He was shown many hens and people tried to convince him that the hen had only two legs. He could not yield though he privately admitted that it had only two legs. Adamant attitude does not heed to logic, fact or reasoning. 
I decided to write this article after debating with colleague, peer professionals and bureaucrats about the likely impact of this policy on the basic scientific attitude in India. During these conversations it became apparent that many bureaucrats do not understand the use for mathematics in basic research despite the fact that they are framing and approving the related policy. For any individual policy makers to try to explain why mathematics is not scientific can only reveal an astonishing degree of narcissism and arrogance.

The present problem arising out of the recent FCS policy is manmade and because of the lack of understating of subjects like mathematics and computer science, among FCS policy makers who have taken a decision that a person with degree of M.Sc. in Mathematics, Master of Computer Application and others are not eligible for consideration for career progress as Scientists under FCS.

Subjects like mathematics and computer science play vital role in research and development in any field of studies. Disrespect or disregard to a science of fundamental nature wherein Indian's contributed significantly, internationally during pre-independent era may disturb basic research ethos of the country which is already many years behind the western world. Domain of a subject is not limited by the name of degree that is awarded to a person by any recognized educational institution in a country. It is determined by the contents of the subject that is taught for the degree. By and large, the content in mathematics for the award of Master Degree in Mathematics and that for the award of Master degree in Computer Application in India is determined by the approved bodies of respective Universities recognized by University Grant Commission. And when the candidates who get the degree are eligible to appear for selection for research fellowship, scientific posts in DRDO, CSIR and other research organizations as per their recruitment rules, then why this item 5 in Frequently Asked Questions (FAQ) published from DOPT on its website http://persmin.nic.in and accessed on September 23, 2011 ?

The remedial action is simple and straight but it requires a lot of efforts on the part of policy makers to realize that. Once they do that, then the simple steps required for restoration of invaluable place of mathematics and computer science in research \& development in India is to incorporate the following correction in the Modified Flexible Complementing Scheme (MFCS) and subsequently released FAQ:

i) Include formal/basic science in the list of qualification for a person to be considered under MFCS [6] along with natural science to exclude any confusion and scope for misinterpretation about the status of mathematics and computer science as science;

ii) Remove item 5 from list of FAQ [5] for FCS released \& published by DOPT on its website http://persmin.nic.in and accessed on September 23, 2011.

\section{CONCLUSIONS}

Nature is innately mathematical and she speaks to us in mathematics. We only need to listen. Because nature is mathematical, any science that intends to describe nature is completely dependent on mathematics. It is impossible to overemphasize this point, and it is why Carl Friedrich Gauss called mathematics "the queen of the sciences". Mathematics plays a pivotal role among sciences, being an indispensable tool to so many other facets of science. Its particular interpretation of the scientific method and its particular thresholds may be quantitatively different from other sciences, but they are qualitatively the same. We mentioned above the quantum theory and Dirac's unified theory. We may ask whether Dirac invented the equation and nature subsequently obeyed Dirac's equation and therefore this must make Dirac God. But Dirac isn't God, therefore he discovered his equation. If Dirac discovered his equation, where did he find it? He found it in nature. For the entire history of the universe, Dirac's equation lay as an undiscovered treasure in the bosom of nature, until Dirac happened chance stamp upon it [15].

Coming to the formal sciences, in general, although they are usually conceptual systems, sometimes lacking empirical content, this does not mean that they have no relation to the real world. But this relation is such that their formal statements hold in all possible worlds whereas, statements based on empirical theories, such as, say, General Relativity or Evolutionary Biology, do not hold in all possible worlds, and may even turn out not to hold in this world. That is why formal sciences are applicable in all domains and useful in all empirical sciences.

In everyday earthly science, because of the eternal possibility of new evidence contradicting old, a theory can only be proven false, never true. Some theories come to be regarded as very likely, but none of them is ever pronounced "true," at least not in science. Mathematical proof stands as an exception to this rule. In Platonic mathematics, because of its separation from nature, it is possible to construct an argument that has the widest possible generality. It applies to the entire set it makes a statement about.

A proof in mathematics has no corollary in the ordinary sciences, because theories about nature are held hostage by nature itself and by the prospect of new evidence. But mathematics and the other sciences have a great deal in common, for example all have the property of falsifiability. I might assert that all primes are odd numbers, but this is easily falsified by 2 , the only even prime. There is only one even prime, but one is not none and my claim is therefore falsified. Also consider that without 2 in the set of primes there would be no even composites. This example is to distinguish, in very simple term, mathematics from other science. In 
mathematics, you can construct a true or false statement, while in other sciences you can only construct statements that are either probably true or definitely false, but never definitely true.

Mathematics does not require any certification from a philosopher or a debater or Techburea or a Bureatech whose professional survival essentially depend on to pretend that nothing is agreed on and anything is open to debate except, of course, for his privilege to debate anything. Sooner this contradiction in MFCS and FAQ is restored better will be for the improvement of scientific culture in the country.

\section{ACKNOWLEDGMENT}

Existence of a problem inspires one to find its solution. One has to look around to know the presence of something worth noticing. The detailed research presented in this paper is made possible by systemic analysis, interpretation and then deliberating on the issue at peer level. I am thankful to them for providing very intellect input on the subject. I am very grateful to all those who have been constantly encouraging and providing required resources for such work in addition to the regular work of the departments which I am carrying out. Special thanks to some of my colleagues who always chant for something new.

\section{REFERENCES}

[1] Ball, D. L., Hill, H.C, and Bass, H. :2005, 'Who knows mathematics well enough to teach third grade, and how can we decide?' American Educator, http://www.aft.org/pubsreports/american_educator/i ssues/fall2005/BallF05.pdf.

[2] Campbell, S.: 2002, 'Constructivism and the limits of Reason: revisiting the Kantian problematic', Studies in Philosophy and Education, 21, 421-445.

[3] Cohen, L., Manion, L., Morrison, K.:2004, Research Methods in Education, 5th ed, Routledge Falmer, London.

[4] Colyvan, M.: 2001, 'The miracle of applied mathematics', Synthese, 127, 265-277.

[5] Department Of Personal \& Training, GOI, Flexible Complementing Scheme, Frequently Asked Question, doa: September 23, 2011.

[6] Department Of Personal \& Training, GOI, Office Order No. FCS-14017/37/2008-Estt-RR dated September 10, 2010, "Modified Flexible Complementing Scheme for Scientists based on the recommendations of the 6Ih Central Pay Commission".

[7] Department Of Personal \& Training, GOI, Office Order No. 2/41/97-PIC dated November 9, 1998, "Flexible Complementing Scheme for Scientists in the various scientific departments -recommendations of the Fifth Central Pay Commission for modification of the scheme -regarding".

[8] Geertz, C.: 1973, The Interpretation of Cultures, Basic Books, New York.
[9] Gray, E. and Tall, D.: 1994, 'Duality, Ambiguity and Flexibility', Journal for Research in Mathematics Education, 26(2), 115-141.

[10] Hill, H.C. and Ball, D. L.:2004, 'Learning mathematics for teaching: Results from California's mathematics professional development institutes', Journal for Research in Mathematics Education 35 (5), 330-351.

[11] Hill, H.C., Rowan, B. and Ball, D.L.:2005, 'Effects of teachers' mathematical knowledge for teaching on student achievement', American Educational Research Journal 42 (2), 371- 406.

[12] J. A. Sethian (1996), Level Set Methods: Evolving Interfaces in Geometry, Fluid Mechanics, Computer Vision, and Materials Sciences, Cambridge University Press.

[13] J. Keener and J. Sneyd (1998), Mathematical Physiology, Springer-Verlag, Berlin.

[14] Jaworski, B.: (2007) 'Theory in developmental research in mathematics teaching and learning: social practice theory and community of inquiry as analytical tools.' Paper presented at CERME 5 (Group 11) in Cyprus 2007.

[15] Karatzas and S. E. Shreve (1998), Methods of Mathematical Finance, Springer-Verlag, New York.

[16] Kumar, V. and Muttoo, S. K., (2009). 'A Data Structure for Graph to Facilitate Hiding of Information in a Graph's Segments -A Graph Theoretic Approach to Steganography'. Int. J. on Computer Network and Distributed System, Inderscience, Vol. 3, No. 3, pp. 268-282.

[17] Kumar, V. and Muttoo, S. K., (2010) 'Graph Theoretic Approach to Steganography to Secure Message Digest', Information Security Journal: A global perspective, Taylor \& Francis, Vol. 19, No. 6, pp. 328-335.

[18] Kumar, V. and Muttoo, S. K., (2011). 'A Graph Theoretic Approach to Sustainable Steganography'. MIS Review: An Int. Journal, Vol. 17, No. 1, pp. 19-37.

[19] Kumar, V. and Sharma, V., (2006). 'Overcoming $64 \mathrm{~K}$ data size limit in handling large spatial data in GISNIC while cleaning and building topology'. Int. J. of Information Technology and Management, Inderscience, Vol. 5, No. 1, pp. 77-86.

[20] Kumar, V., (2010). 'Restricted Backtracked Algorithm to Find Hamiltonian Circuit in Undirected Graph'. BVICAM Int. J. of Information Technology, India, Vol. 2, No. 2, pp. 23-32.

[21] Lerman, S.: 1996, 'Inter subjectivity in Mathematics Learning: A Challenge to the Radical Constructivist Paradigm?', Journal for Research in Mathematics Education, 27(2), 133-150.

[22] M. H. G. Hoffmann, J. Lenhard y F. Seeger (eds.), Activity and Sign. Grounding Mathematics Education, Springer, New York, pp. 137-152.

[23] Muttoo, S. K. and Kumar, V., (2010) 'Hamiltonian Graph Approach to Steganography', International Journal of Electronic Security and Digital Forensic, Inderscience, Vol. 3, No. 4, pp. 311 - 332. 
[24] Muttoo, S. K. and Kumar, V., (2010). 'Hiding Message in Map along pre Hamiltonian Path'. Int. J. of Information Security and Privacy, Idea Group USA, Vol. 4, No. 4, pp. 21-34.

[25] Radford, L.: 2003, 'On the epistemological limits of language: Mathematical knowledge and social practice in the Renaissance', Educational Studies in Mathematics, 52(2), 123-150.

[26] Radford, L.: 2003a, 'Gestures, speech and the sprouting of signs' Mathematical Thinking and Learning, 5(1), 37-70.

[27] Radford, L.: 2006, 'Algebraic Thinking and the Generalization of Patterns: A Semiotic Perspective', in S. Alatorre et al. (Eds.), Proceedings of the 28th Conference of the International Group for the Psychology of Mathematics Education, North American Chapter, Mérida, Vol. 1, pp. 2-21 (Plenary Lecture).

[28] Rowland, T., Huckstep, P. and Thwaites, A. :2004, 'Reflecting on prospective elementary teachers' mathematics content knowledge: the case of Laura', Proceedings of the 28th International Conference, Psychology of Mathematics Education, Vol. 4, Bergen, Norway, pp. 121-128.

[29] S. K. Muttoo, Kumar, V., (2012). "Watermarking Digital Vector Map Using Graph Theoretic Approach", Annals of GIS, Taylor \& Francis. Vol. 18, No. 2 pp. 135-146.

[30] Sfard, A.: 1991, 'On the dual nature of mathematical conceptions', Educational Studies in Mathematics, 22, 1-36.

[31] Wartofsky, M.: 1979, Models, Representation and the Scientific Understanding, D. Reidel, Dordrecht.

[32] Willinger and V. Paxson (1998), Where mathematics meets the Internet, Notices of the American Mathematical Society 45, 961---970.

[33] Yackel, E. and Cobb, P.: 1996, 'Socio-mathematical norms, argumentation, and autonomy in mathematics', Journal for Research in Mathematics Education, 27(4), 458-477.

Dr. Vinay Kumar is a Scientist in National Informatics Centre, DIT, MoCIT, Government of India. He completed his MCA from JNU and Ph.D. in Computer Science from University of Delhi. He has authored a book on discrete mathematics and has contributed many research papers to referred journals and conferences. His area of interest is graph algorithm, steganography, data security, data privacy and discrete mathematics. 